\title{
Review of gasification modelling and equilibrium model implementation to predict rice husk syngas composition
}

\section{Laetitia ZOUNGRANA ${ }^{1,2, *}$, Sayon Dit Sadio SIDIBE ${ }^{2}$, Yohan RICHARDSON ${ }^{2}$, Yezouma COULIBALY ${ }^{2}$}

\author{
${ }^{1}$ Institute of mechanics matériels and civil engeneering, Université catholique de Louvain, Louvain-la-Neuve, \\ Belgique \\ ${ }^{2}$ Laboratoire Énergie Renouvelable et Efficacité Énergétique, Institut 2iE, Ouagadougou, Burkina Faso \\ *laetitia.zoungrana@uclouvain.be/laetitia.zoungrana@,2ie-edu.org
}

\section{INFOS SUR L'A R T I C L E}

Historique de l'article:

Reçu le : 31 juillet 2019

Reçu en format revisé le : 23 décembre 2019

Accepté le : 27 décembre 2019

Keywords: Gasification, Downdraft, Model,

Rice husk, West Africa.

\begin{abstract}
A B S T R A C T
In West Africa, biomass has a large potential as a source of renewable energy. One of the best ways to upgrade biomass is through gasification process which stands out as one of the most promising technologies for green power production. In West Africa's economic context, fixed bed downdraft reactor has real advantages because of it energy efficiency and it applicability to small power units. The challenge of developing and implementing this type of gasifier is the optimization of the process. To that end, different models exist and can allow to apprehend the processes of thermochemical transformation of biomass and physical parameters influencing the reactions within the gasifier. For this study, we implemented the equilibrium model which gives a prediction of the syngas species percentage. For the two main species of syngas, the volume fraction of carbon monoxide was $20 \%$ while dihydrogen was $11 \%$ for an equivalence ratio of 0.3 .
\end{abstract}

\section{INTRODUCTION}

These recent years, the energy needs are expanding rapidly due to a substantial increase of the world's population together with a gradual improvement of the overall socio-economic context. Thus, the satisfaction of energy needs is still not a reality for 1.1 billion people worldwide among whose $90 \%$ live in the developing countries of sub-Saharan Africa(International Energy Agency, 2017). These alarming figures have led to the adoption of the United Nations Sustainable Development Goals, which have placed access to energy as a key of sustainable development and planned access to affordable, sustainable and modern energy for all by 2030 (United Nations, 2015). In sub-Saharan Africa, and particularly in West Africa, energy demand is real because households have multiple unmet energy needs, particularly for cooking, lighting, heating, transportation and telecommunication. It follows that opening these populations to adequate energy sources will have a very important impact on the development opportunities as well as on the improvement of their quality of life. Indeed, there is a strong correlation between access to energy and socio-economic development through income-generating activities, production and market income, the household economy, health, education and access to telecommunications (Dasappa, 2011; Riva et al., 2018).The operation of gasification systems adapted to the local environmental context can be considered as a means of achieving energy self-sufficiency in this region. Indeed, biomass gasification is well adapted to large scale power units but also to small and medium scale energy productions. In addition, sub-Saharan Africa has a large source of biomass that could be useful for energy production purposes (CIFOR, 2005).

Regardless of the system and the gasification agent used, the gasification process is globally the same: biomass is introduced into the reactor and heated to high temperatures. Temperatures increase transform biomass through several stages to produce a synthesis gas called syngas which will be collected and converted energetically. Four thermochemical steps will happen from introduction of biomass to syngas. These steps remain fundamentally the same but may vary in spatial and temporal configuration depending on the type of gasifier. These steps are drying, pyrolysis, oxidation and reduction. The explanation of these steps is based on Susastriawan and Purnomo review of small-scale downdraft gasification (Susastriawan, Saptoadi, and Purnomo, 2017).

Biomass is firstly dried at temperature around $110^{\circ} \mathrm{C}$ with the heat from the combustion zone and the interstitial water contained in the fuel is released as 
vapor. Thus, the amount of moisture released $\left(\mathrm{mH}_{2} \mathrm{O}(\mathrm{l})\right)$ corresponds to the formed water vapor $\left(\mathrm{mH}_{2} \mathrm{O}(\mathrm{g})\right)$. The moisture content of each biomass depends of its physical characteristics; normally, the appropriate water content for a fuel in a downdraft gasifier is between 5 and $35 \%$.

Secondly, the thermal decomposition of biomass occurs without an oxidant in a step called pyrolysis. The heat required for this step comes again from the combustion zone. During pyrolysis, at temperatures between 200 and $700{ }^{\circ} \mathrm{C}$, biomass particles are decomposed into char, tars and most of the time in condensable gases which in part subsequently become incondensable gases by thermal cracking. However, in general, the by-products formed after pyrolysis depend on the range of temperatures reached, the pressure, the residence time and the heat losses of the reactor (Anil K. Rajvanshi, 1986).

The third stage of the process is the oxidation. This step is very important because it determines the type and quality of the final products. It occurs between 800 and $1400{ }^{\circ} \mathrm{C}$ and during combustion, volatile biomass is oxidized and gaseous such as $\mathrm{CO}, \mathrm{H}_{2}, \mathrm{CO}_{2}$ and $\mathrm{H}_{2} \mathrm{O}$ are formed. Hydrogen also combines with oxygen to produce water vapor. The choice of the oxidant for this step can influence the properties and the quality of the synthesis gas obtained at the end of the gasification.

Reduction or gasification is the last step in the process of thermochemical transformation of biomass. In the reduction area, solid carbon is converted into syngas. Several reactions, mainly of endothermic nature, lead to the formation of syngas consisting mainly of $\mathrm{CO}, \mathrm{H}_{2}$ and $\mathrm{CH}_{4}$. Tars are the main obstacle to the use of syngas for power generation applications because too much tar particles in the gas increase a risk of clogging fuel lines, filters and the engine. However, several tar reduction methods have been developed for mechanical removal, catalytic cracking, plasma methods or thermal cracking around $1000{ }^{\circ} \mathrm{C}$.

In the following section, an overview of the different types of gasifiers and the different models for gasification simulation are given with an implementation of one of them namely thermodynamic equilibrium model.

\section{MATERIAL AND METHOD}

We firstly reviewed the different types of gasifiers and the different models used to simulate gasification. Then, in a second part, we implemented the thermodynamic equilibrium model with Aspen Plus ${ }^{\circledR}$ software.

\subsection{Review of fixed bed gasifiers}

Depending on the properties of the biomass used and on the syngas applications, there are two main types of gasifiers: fixed bed gasifier and moving bed gasifier. The conversion steps described above remain fundamentally the same but, their extent and configuration change with the gasifier. For moving beds, the biomass is often reduced to small diameters particles (millimeter order) and the gasifying agent is introduced at high speed. Depending on gas velocity, there are variants of moving bed gasifiers as bubbling fluidized bed, circulating fluidized bed or entrained flow. In moving bed gasifiers, the solid behaves like a fluid and there is an excellent mixing of fuel and gasifying agent resulting in a good carbon conversion; however, it remains suitable for high power installations.

At the opposite, fixed beds gasifiers have been reported for small scale heat and power applications. There are three variants of fixed bed named downdraft, updraft and cross draft gasifiers. The last one has very few applications because it only advantage is the good permeability of the fuel bed (Sansaniwal et al., 2017). However, regardless on the variant, the fixed bed gasification process involves a grid to maintain the biomass, fuel and oxidizer feed units, an ash collection unit and an outlet gas unit. In these processes, pressure does not exceed $30 \mathrm{~atm}$, velocities are low, residence time of the biomass is relatively long and largest particles can be allowed in the reactor.

\section{a. Updraft gasifiers}

In the updraft gasifier process (Fig.1a), the oxidizer is injected below the fuel maintaining grid and the produced gas is extracted by the top of the reactor. This allows biomasses with high moisture content because the flow of hot gases through the biomass contributes to dry the incoming combustible and to decrease the temperature of the syngas. Thus, the outlet gas temperature is relatively low (200-300 ${ }^{\circ} \mathrm{C}$ ) because they do not pass through oxidation zone which explain their high tars contain. Therefore, in this design, the main use of this syngas is in a burner for heat production.

\section{b. Downdraft gasifiers}

Biomass is introduced at the top of the reactor, the syngas is collected at the bottom passing through the high temperature of the oxidation zone which permits tars thermal cracking (M. Bassil Georgio, 2012; Sansaniwal et al., 2017). The oxidant can be injected by the top for stratified downdraft gasifier variant (Fig.1b) or through the sides generally one-third of the total height from the grid for Imbert downdraft gasifier (Luc Gerun, 2007). The Imbert gasifier is a specificity of fixed beds because they have a throat at the combustion zone (Fig.1c). The throat increases the residence time of combustible by maintaining the biomass as a support. It also allows a good combustion by well mixing fuel and oxidant because the oxidant injection pipes reach the heart of the fuel mass for a better ignition of the area. The passage of produced gases in the hot zone of reduction permits to reduce tars in the syngas by thermal cracking. This resulting syngas with low tar ratios around $1 \mathrm{~g}$. $\mathrm{Nm}^{-3}$ can be used for variable applications such as motor applications for power generation after cleaning unit to remove remaining impurities. 
Downdraft gasifiers are quite frequently used in Africa's energy platforms. Indeed, they are well adapted to local artisanal production while having a low yield of tars for the small-scale electrical production. Some are at the experimental stage and others are working actively for energy needs. In Benin, the Songhai center has a biomass gasification power generation plant with a capacity of $32 \mathrm{kWe}$. The gasification prototype uses acacia wood, coconut shells and palm kernels. This system with integrated electricity production is economically competitive with the national electricity grid (Aristide Dejean, 2013).In the southern of Benin, in Sékou locality, a downdraft gasification platform has been installed. Corn raffle and pieces of wood are used as fuel and this site provides a power of $11 \mathrm{KW}$ and is mainly intended for the production of electrical energy through a gas engine.
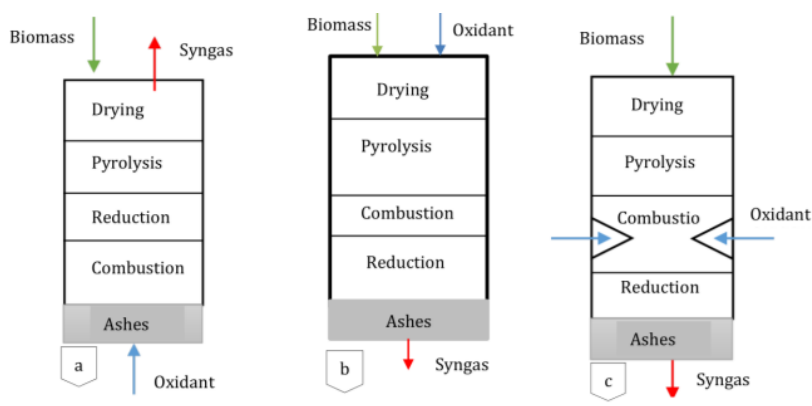

Fig.1. (a) Updraft reactor;(b) Stratified downdraft;(c) Imbert downdraft reactor.

\section{c. Downdraft gasifiers improvements}

A study conducted by Galindo et al on a downdraft gasifier with a two-stage air supply showed better results in terms of tar cracking, producing a good qualitative gas (Galindo et al., 2014).In parallel, the Asian Institute of Technology has developed a co-current gasifier with multiple air injections. This technology allows the differentiation of the pyrolysis, oxidation and reduction stages in the same reactor, resulting in a tar concentration 40 times less than a conventional reactor (Luc Gerun 2007). Yang et al. have shown that an increase of the oxidant temperature results in a faster ignition, a higher gasification yield and higher molar fractions of $\mathrm{H}_{2}, \mathrm{CO}$ and $\mathrm{CmHn}$, thus a high LHV (Weihong Yang et al., 2005).

\subsection{Review of gasification models}

The choice for a gasifier design model is very decisive for the results that will be obtained after modeling under the defined conditions. Indeed, a model is very often characterized by the specificity that it allows to apprehend. For Boumeddane, gasification models are essentially based on four ways as model of Artificial Neural Networks, thermodynamic equilibrium model, kinetic model and Computational Fluid Dynamic model (Boumeddane, 2011). In a global way, these different models are distinguished by the fact that they make possible to apprehend the processes of biomass thermochemical transformation and for others the physical parameters influencing the reactions within the gasifier.

Then, model of neural networks commonly called ANN (Artificial Neural Networks) is a computational method for solving systems. The design for this method is inspired by the human brain architecture and based on mathematical equation series used to simulate biological processes such as learning and memory (Puig-Arnavat and Bruno, 2015). ANN is characterized as nonmechanical, unbalanced and non-analytical (Baruah and Baruah, 2014). Although in theory they can produce numerical results to predict the composition of a gasifier syngas, the use of neural networks for biomass gasification is rare. Indeed, the performance of the ANN depends solely on its memory knowing that its formation requires a large number of experimental data. Thus, neural networks cannot be a viable option for modeling a technology such as biomass gasification with limited numbers of experimental data sets (Patra and Sheth, 2015).

\section{a. Thermodynamic equilibrium model}

The thermodynamic equilibrium model is used to calculate the theoretical yield that can be achieved for a desired product in a reagent system. Calculations in this model are independent of the design of the gasifier and only allow to study the influence of fuel and process parameters (Patra and Sheth, 2015). Equilibrium models are based either on equilibrium constants calculations or on the minimization of Gibbs free energy. The first method is called stoichiometric approach because it requires a precise specification of all the chemical reactions and species involved in the process. However, the Gibbs free energy minimization method does not require exact knowledge of chemical reaction mechanisms to determine equilibrium synthesis gas composition that is why it is said to be nonstoichiometric. Thus, the choice of the approach will depend on the complexity of the reaction mechanisms to solve (Fortunato et al., 2017).However, regardless on the chosen method, the predictive results remain relatively similar.

Zainal et al. worked on the equilibrium model to predict syngas composition and its calorific value with wood chips as fuel. They concluded that the calorific value of the gas decreases as the temperature increases and the carbon monoxide content decreases linearly within creasing fuel moisture (Zainal et al., 2001).

Fortunato et al. have described a thermodynamic equilibrium model for a downdraft gasifier where the pyrolysis, oxidation and reduction phases have been implemented separately. In the work of Zainal et al., authors assume the reactions reach thermodynamic equilibrium with the assumption that all pyrolysis products have reacted in the reduction zone (Fortunato et al., 2017). 
Adnan et al. have studied a thermodynamic model including tar simulations with the software Aspen plus. They worked on a downdraft gasifier with varying gasifying agents (steam or oxygen) in the different zones. A good performance is observed when the steam with a ratio $(\mathrm{S} / \mathrm{C}=0.2)$ is injected in the reduction area (Adnan et al. 2017). The equilibrium model is appropriate in the calculation of thermochemical conversion properties in a dynamic system but does not allow to describe the physical phenomena which nevertheless influence the results at the exit of the gasifier. However, this limit to the equilibrium model can be solved by using kinetic models (Fortunato et al., 2017).

\section{b. Kinetic model}

The kinetic model has been discussed in the review by Patra and Sheth (Patra and Sheth, 2015); thus, the inadequacy of the equilibrium model to correlate the reactor physical parameters leads to use kinetic models to evaluate and mimic the gasifier behavior. Thus, parameters such as reaction rate, residence time, internal hydrodynamics and reactor dimensions are considered in kinetic modeling.

This model has the ability to predict the behavior and the composition of species inside the reactor in each relational zone (Baruah and Baruah, 2014).

Yucel and Hastaoglu used kinetic modeling to study the transport of solid and gaseous flows inside an Imbert gasifier. They also take into account the variable cross section of the reactor, the contribution of the walls in the energy balance and the contribution of the oxidizing agent in the mass and energy balance. This study allowed the modeling of a reactor with a throat very realistically because it is a complex system including many variables. As a result, the presence of the throat allows a better distribution of heat while reducing heat loss (Yucel and Hastaoglu, 2016).

Giltrap et al. have proposed a kinetic model predicting the composition of syngas and the temperature inside a co-current reactor, they used the reactions kinetic parameters obtained by Wang and Kinoshita (Wang and Kinoshita, 1993). The model has been developed specifically for the gasifier reduction zone and it has been assumed that all pyrolysis products are completely cracked (Giltrap, McKibbin, and Barnes, 2003). Jayah et al. have proposed a kinetic model composed of two submodels for the pyrolysis and gasification zones. The pyrolysis zone sub-model is used to determine the maximum temperature and gaseous product concentration and these results are inputs to the sub-model of the gasification zone. The sub-model of the gasification zone include a description of physical and chemical processes, flow equations, transport phenomena and conservation principles (Jayah et al., 2003). Tinaut et al. have developed a model for steady-state biomass gasification. This model introduces the main phenomena allowing the degradation of biomass into gaseous fuel and considers that the product gas can be used in internal combustion engines. They have also studied the influence of process parameters, such as biomass particle diameter, air flow velocity, gasifier geometry and experimental results have validated the model (Tinaut et al., 2008).

Sharma proposed a particle bed model for a downdraft biomass gasifier to predict parameters as pressure loss in the bed, biomass conversion rate, and temperature and concentration profiles. This model consists of three main stages; the first one corresponds to the estimation of materials flows evacuated from the gasifier. The second is the resolution of energy equation on each control volume obtained after discretization in space. Finally, the third stage solves all the equations describing the phenomena taking place in the gasifier such as drying, pyrolysis and the various oxidations and reductions (Sharma, 2011). Salem and Paul used an integrated kinetic model to predict gas composition, tar content, temperature and height of each zone of a gasifier (Salem and Paul, 2018).

\section{c. Computational Fluid Dynamics}

Computational Fluid Dynamics (CFD) is a numerical calculation of differential equations that govern a fluid motion (INERIS, 2015). This model considers mass conservation, momentum conservation species dynamics and energy flows over a defined region. In addition, complex parameters such as drag force, biomass porosity and turbulence are also considered.

Murugan and Sekhar used Fluent ${ }^{\circledR}$ to design a rice husk downdraft gasifier. They modeled species transport by incorporating all the parts of the reactor. In order to simplify the solution, they made assumptions such as constant flux, adiabatic wall and turbulent flow. The domain was meshed with 25000 cells then the number of cells was increased in order to refine the cells for a better simulation of the $\mathrm{CO}$ and $\mathrm{H}_{2}$ mass fractions. In this study, the equivalence ratio was maintained at 0.30 and the boundary conditions were also held constant (Murugan and Joseph Sekhar, 2017).

Silva et al. have used ANSYS Fluent ${ }^{\circledR}$ for their CFD modeling to obtain an unsteady solution. They discretized the system in finite volumes and then used the algorithm SIMPLE to solve equations and simulate the gas phase reactions (Joas Silva et al., 2017).

\subsection{Thermodynamic equilibrium modeling with Aspen plus ${ }^{\circledR}$ software}

A practical simulation of thermodynamic equilibrium has been developed in this study with local fuel characteristics. The aim is to predict the different products behavior during the process, for this, Aspen plus ${ }^{\circledR}$ has been used. Aspen Plus ${ }^{\circledR}$ (Advanced System for Process Engineering), built by Aspen technology, is a static and dynamic processes simulation software.

The gasification process is simulated as separated blocks in Aspen plus, representing the different zones of 
the gasifier. In each block, physical data are defined and all the blocks are linked by streams. Then the outlet stream property is calculated based on the inlet characteristics and on the block physical properties.

\section{Model establishment}

The thermodynamic equilibrium model is used to calculate the theoretical yield of the products that can be formed after gasification.

In our model, we have defined four blocks. Two are reactors blocks (RYIELD and RGIBBS). The fuel used is West African rice husk, characterized in Titiloye et al. study (Tables 1, 2) (Titiloye, et al., 2013).

Table 1. Rice husk proximate analysis

\begin{tabular}{|l|c|c|l|c|}
\hline Biomass & Moisture & Volatile matter & Ash & $\begin{array}{l}\text { Fixed } \\
\text { carbon }\end{array}$ \\
\hline Rice husk & 8.59 & 58.22 & 24.71 & 8.48 \\
\hline
\end{tabular}

Table2. Rice husk ultimate analysis

\begin{tabular}{|l|l|l|l|l|l|l|}
\hline Elements & $\mathrm{C}$ & $\mathrm{H}$ & $\mathrm{N}$ & $\mathrm{S}$ & $\mathrm{Cl}$ & $\mathrm{O}$ \\
\hline Percentage & 34.90 & 5.15 & 0.31 & 0.64 & $<0.01$ & 59.00 \\
\hline
\end{tabular}

The rice husk is considered as a nonconventional compound in the reactor, the tool HCOALGEN and DCOALIG permit to estimate the enthalpy and density of the fuel based on its proximate and ultimate analyses.

First, rice husk is decomposed into conventional compounds in the Ryield block and gasified in the Rgibbs block which calculates the products at thermochemical equilibrium. In Rgibbs reactor, the methanation and the water-gas shift reactions are the two chemical equilibrium reactions used. The flow leaving the reactor at equilibrium is treated to separate solid particles in a Cyclone and to cool down in the Cooler block. So, the syngas is collected after a condensation and removal of water thanks to the block Separato (Fig.2).

The main assumptions for process simulation are:

- The blocks are adiabatic;

- The blocks have uniform temperature and a perfect mixing of components;

- Residence time is long enough to reach the thermodynamic equilibrium in the R-Gibbs block;

- All the solid carbon has reacted;

- The gases are all considered as ideal.

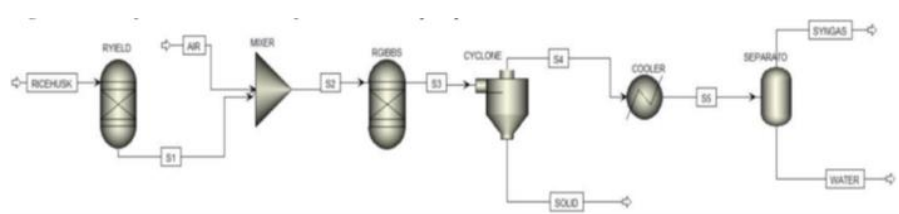

Fig.2. Gasification simulation flow sheet in Aspen plus.

\section{RESULTS AND DISCUSSION}

The simulation results show a large conversion of $\mathrm{CH}_{4}, \mathrm{CO}_{2}$ fractions by the temperature. At the opposite, there is an increase of carbon monoxide and dihydrogen mole flow which are major constituent gases of syngas with a peak of dihydrogen value between 800 and $840^{\circ}$ C. There is a reforming of the water vapor beyond 720 degrees (Fig.3).

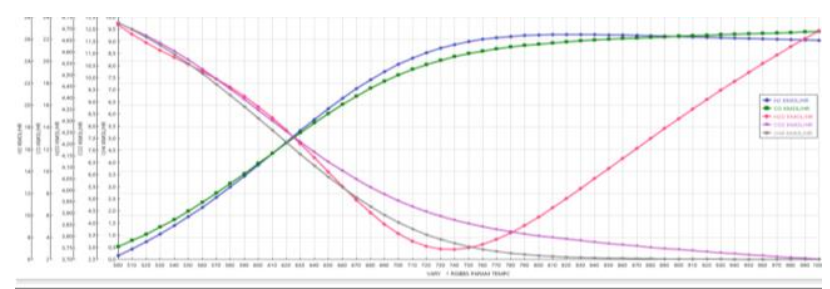

Fig.3. Syngas components mole flow related to temperature.

At equilibrium temperature, by increasing the equivalence ratio, the volume percentage of $\mathrm{CO}$ and $\mathrm{H} 2$ are respectively $20 \%$ and $11 \%$ for $\mathrm{ER}=0.3$ (Fig.4). At equilibrium and 0.3 equivalence ratio, $\mathrm{CO}$ mass percentage is $40 \%$ and $1.7 \%$ for $\mathrm{H}_{2}$ because of the low molecular weight of dihydrogen (Fig.5) and assuming that mass fractions are on ash free based.

We have calculated the equivalence ratio of air and the syngas lower heating value based of the following formulas:

$$
\begin{gathered}
E R=\frac{\text { weight air } / \text { weight dry biomass }}{\text { stoichiometric air } / \text { biomass ratio }} \\
\mathrm{LHV}=\mathrm{xH}_{2} * \mathrm{LHVH}_{2}+\mathrm{xCO} * \mathrm{LHVCO}+\mathrm{xCH}_{4} \\
* \mathrm{LHVCH}_{4}
\end{gathered}
$$

The lower heating value depends on the volume percentage of each gas component (xi) and the lower heating values of each gas (LHVi) (Fig.6). Then, the LHV decreases with the increase of equivalence ratio.

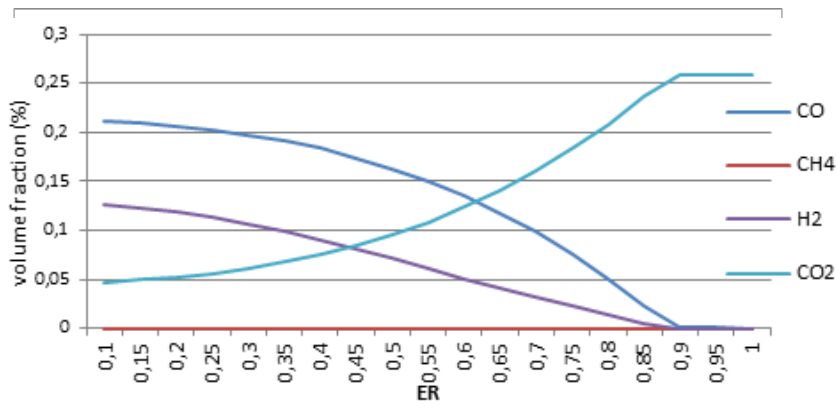

Fig.4. Syngas components volume fractions related to equivalence ratio variation.

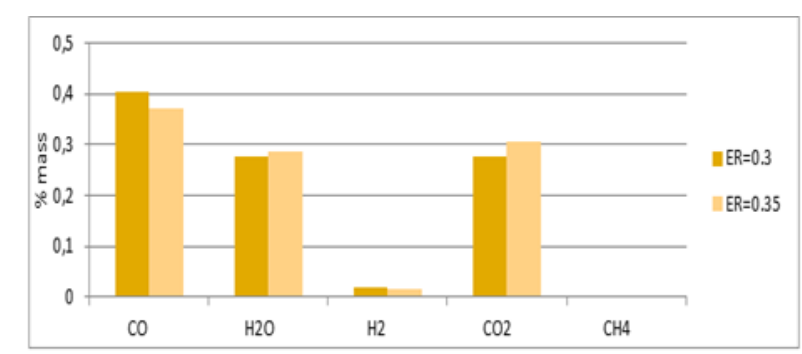

Fig.5. Syngas gases mass percentage according to ER 


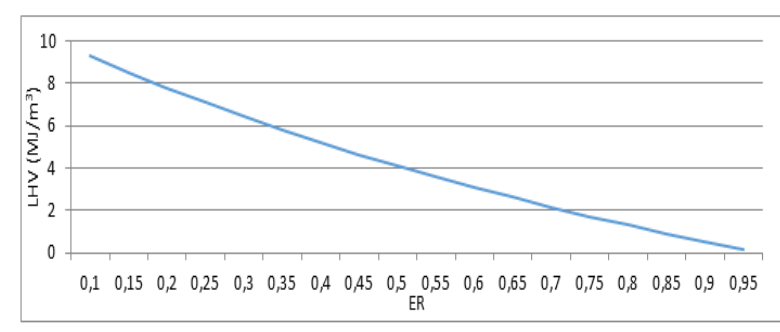

Fig.6. Syngas LHV variation with $E R\left(M J / m^{3}\right)$

\section{- Model validation}

The accuracy of the model is checked by comparison of gas composition predicted for the two main species of syngas $\left(\mathrm{CO}\right.$ et $\left.\mathrm{H}_{2}\right)$ with the experimental results of(Ma et al., 2015) (Table 3)

Table 3. comparative table of predicted and experimental syngas

\begin{tabular}{|l|l|l|l|}
\hline & Our model & Ma et al & $\begin{array}{l}\text { Mean } \\
\text { error } \boldsymbol{\sigma}\end{array}$ \\
\hline $\mathrm{CO}$ & $20 \%$ & $14 \%$ & $4.2 \%$ \\
\hline $\mathrm{H}_{2}$ & $11 \%$ & $10 \%$ & $0.7 \%$ \\
\hline
\end{tabular}

$$
\begin{gathered}
V=\frac{1}{n} \sum_{i=1}^{n}(x i-\bar{x})^{2} \\
\sigma=\sqrt{V}
\end{gathered}
$$

Since the average standard deviation (eq.3-4) between the predictions of our model and the experimental results of Ma et al. is low, these differences can be explained. In this case, it can mostly result by the difference in the input data, particularly on the immediate and ultimate analyzes of the rice husk used by authors (Table 4). Indeed, the differences in the proportions of carbon, hydrogen and oxygen cause the formation of compounds in slightly different percentages.

Table 4. Ultimate and Proximate Analysis of Rice Husk (Ma et al.)

\begin{tabular}{|l|l|l|l|}
\hline $\begin{array}{l}\text { Ultimate } \\
\text { Analysis }\end{array}$ & $\begin{array}{l}\text { Mass \%, } \\
\text { dry basis }\end{array}$ & $\begin{array}{l}\text { Proximate } \\
\text { Analysis }\end{array}$ & $\begin{array}{l}\text { Mass \%, } \\
\text { dry basis }\end{array}$ \\
\hline Carbon & 37,65 & Volatile & 61,78 \\
\hline Hydrogen & 5,13 & $\begin{array}{l}\text { Fixed } \\
\text { carbon }\end{array}$ & 8,08 \\
\hline Oxygen & 55,4 & Ash & 30,18 \\
\hline \multirow{2}{*}{} & $\begin{array}{l}\text { Moisture } \\
\text { Content }\end{array}$ & 4,55 \\
\cline { 2 - 4 }
\end{tabular}

\section{CONCLUSION}

The thermodynamic equilibrium model has been used by many authors to predict the composition of syngas or to deduce calorific value of synthesis gas. The kinetic model in addition on predicting syngas composition, uses reactions kinetic parameters to correlate the gasifier behavior. As for the Computational Fluid Dynamics model, it is a numerical calculation of differential equations which describe mass conservation, species dynamics, energy flows, hydrodynamics or turbulence in a system. The simulation results show the reduction of $\mathrm{CH}_{4}$ and $\mathrm{CO}_{2}$ for long residence time and high temperatures. The volume percentage of $\mathrm{CO}$ and $\mathrm{H}_{2}$ are respectively $20 \%$ and $11 \%$ for air equivalence ratio of 0.3 . These theoretical results allow us to have a good prediction of the gas composition for future projections concerning this syngas use.

\section{REFERENCES}

Adnan, Muflih A., Herri Susanto, Housam Binous, Oki Muraza, and Mohammad M. Hossain. 2017.

"Enhancement of Hydrogen Production in a Modified Moving Bed Downdraft Gasifier - A Thermodynamic Study by Including Tar." International Journal of Hydrogen Energy 42 (16): 10971 - 10985.

https://doi.org/https://doi.org/10.1016/j.ijhydene.2017 .01 .156 .

Anil K. Rajvanshi. 1986. "Biomass Gasification.” In Alternative Energy in Agriculture, 83-102. India: Ed D. Yogi Goswami CRC Press.

Aristide DEJEAN. 2013. "Tests Technico-Économiques Sur La Plateforme Gazeifieur : De L'étude de La Ressource À L'utilisation Du Gaz Dans Un Moteur Pour La Production D'électricité." https://www.memoireonline.com/11/13/7877/Teststechnico-economiques-sur-la-plateforme-gazeifieurde-letude-de-la-ressource--lutili.html.

Baruah, Dipal, and D.C. Baruah. 2014. "Modeling of Biomass Gasification: A Review." Renewable and Sustainable Energy Reviews 39 (November): 806-15. https://doi.org/10.1016/j.rser.2014.07.129.

Boumeddane, Boussad. 2011. "Investigations Numériques de L'auto Inflammation Des Mélanges Méthane/air En Mode HCCI."

CIFOR, Center for International Forestry Research. 2005. "Les Forêts et Le Développement de l'Afrique", 2005.

Dasappa, S. 2011. "Potential of Biomass Energy for Electricity Generation in Sub-Saharan Africa." Energy for Sustainable Development 15 (3): 203-13. https://doi.org/10.1016/j.esd.2011.07.006.

Fortunato, B., G. Brunetti, S.M. Camporeale, M. Torresi, and F. Fornarelli. 2017. "Thermodynamic Model of a Downdraft Gasifier.” Energy Conversion and Management 140 (May): 281-94. https://doi.org/10.1016/j.enconman.2017.02.061.

Galindo, Ana Lisbeth, Electo Silva Lora, Rubenildo Viera Andrade, Sandra Yamile Giraldo, Rene Lesme Jaén, and Vladimir Melian Cobas. 2014. "Biomass Gasification in a Downdraft Gasifier with a TwoStage Air Supply: Effect of Operating Conditions on Gas Quality.” Biomass and Bioenergy 61 (February): 236-44. https://doi.org/10.1016/j.biombioe.2013.12.017.

Giltrap, D. L., R. McKibbin, and G. R. G. Barnes. 2003. "A Steady State Model of Gas-Char Reactions in a 
Downdraft Biomass Gasifier.” Solar Energy 74 (1): 85-91.

International Energy Agency. 2017. "World Energy Outlook 2017."

Jayah, T.H., Lu Aye, R.J. Fuller, and D.F. Stewart. 2003. "Computer Simulation of a Downdraft Wood Gasifier for Tea Drying." Biomass and Bioenergy 25 (4): 45969. https://doi.org/10.1016/S0961-9534(03)00037-0.

Joas Silva, José Teixeira, Senhorinha Teixeira, Simone Preziati, and Joao Cassiano. 2017. "CFD Modeling of Combustion in Biomass Furnace.pdf”, 2017.

Luc Gerun. 2007. “Etude Numérique et Expérimentale de La Valorisation Énergétique de La Biomasse Par Gazéification". UNIVERSITE DE NANTES.

M. Bassil Georgio. 2012. “Gazeification de La Biomasse : Elimination Des Goudrons Par Lavage, Étude Expérimentale et Modélisation". Lyon, France: Université Claude Bernard de Lyon 1.

Ma, Zhongqing, Jiewang Ye, Chao Zhao, and Qisheng Zhang. 2015. "Gasification of Rice Husk." BioResources 10(2), 2015.

Murugan, P.C., and S. Joseph Sekhar. 2017. "Species Transport CFD Model for the Gasification of Rice Husk ( Oryza Sativa ) Using Downdraft Gasifier." Computers and Electronics in Agriculture 139 (June): 33-40. https://doi.org/10.1016/j.compag.2017.05.004.

Patra, Tapas Kumar, and Pratik N. Sheth. 2015. "Biomass Gasification Models for Downdraft Gasifier: A Stateof-the-Art Review." Renewable and Sustainable Energy Reviews 50 (October): 583-93. https://doi.org/10.1016/j.rser.2015.05.012.

Puig-Arnavat, Maria, and Joan Carles Bruno. 2015. "Artificial Neural Networks for Thermochemical Conversion of Biomass." In Recent Advances in Thermo-Chemical Conversion of Biomass, 133-56. Elsevier. http://linkinghub.elsevier.com/retrieve/pii/B97804446 32890000053.

Riva, Fabio, Helene Ahlborg, Elias Hartvigsson, Shonali Pachauri, and Emanuela Colombo. 2018. "Electricity Access and Rural Development: Review of Complex Socio-Economic Dynamics and Causal Diagrams for More Appropriate Energy Modelling." Energy for Sustainable Development 43 (April): 203-23. https://doi.org/10.1016/j.esd.2018.02.003.

Salem, Ahmed M., and Manosh C. Paul. 2018. “An Integrated Kinetic Model for Downdraft Gasifier Based on a Novel Approach That Optimises the Reduction Zone of Gasifier.” Biomass and Bioenergy 109 (February): 172-81. https://doi.org/10.1016/j.biombioe.2017.12.030.

Sansaniwal, S.K., K. Pal, M.A. Rosen, and S.K. Tyagi. 2017. "Recent Advances in the Development of Biomass Gasification Technology: A Comprehensive Review." Renewable and Sustainable Energy Reviews 72 (May): 363-84.

https://doi.org/10.1016/j.rser.2017.01.038.
Sharma, Avdhesh Kr. 2011. "Modeling and Simulation of a Downdraft Biomass Gasifier 1. Model Development and Validation." Energy Conversion and Management 52 (2): 1386-96. https://doi.org/10.1016/j.enconman.2010.10.001.

Susastriawan, A.A.P., Harwin Saptoadi, and Purnomo. 2017. "Small-Scale Downdraft Gasifiers for Biomass Gasification: A Review." Renewable and Sustainable Energy Reviews 76 (September): 989-1003. https://doi.org/10.1016/j.rser.2017.03.112.

Tinaut, Francisco V., Andrés Melgar, Juan F. Pérez, and Alfonso Horrillo. 2008. "Effect of Biomass Particle Size and Air Superficial Velocity on the Gasification Process in a Downdraft Fixed Bed Gasifier. An Experimental and Modelling Study." Fuel Processing Technology 89 (11): 1076-89. https://doi.org/10.1016/j.fuproc.2008.04.010.

United Nations. 2015. "Sustainable Development Goals." 2015.

http://www.un.org/sustainabledevelopment/fr/energy/.

Wang, Y., and C. M. Kinoshita. 1993. "Kinetic Model of Biomass Gasification.” Solar Energy 51 (1): 19-25.

Weihong Yang, Anna Ponzio, Carlos Lucas, and Wlodzimierz Blasiak. 2005. "Performance Analysis of a Fixed-Bed Biomass Gasifier Using HighTemperature Air", 2005.

Yucel, Ozgun, and Mehmet Alaittin Hastaoglu. 2016. "Kinetic Modeling and Simulation of Throated Downdraft Gasifier." Fuel Processing Technology 144: 145 - 154 . https://doi.org/https://doi.org/10.1016/j.fuproc.2015.1 2.023 .

Zainal, Z. A., R. Ali, C. H. Lean, and K. N. Seetharamu. 2001. "Prediction of Performance of a Downdraft Gasifier Using Equilibrium Modeling for Different Biomass Materials." Energy Conversion and Management 42 (12): 1499-1515. 